\title{
The Potential Distribution and Westernmost Record of Eremias strauchi Kessler, 1878 in Turkey
}

\author{
Muammer KURNAZ*,1, Ali İhsan EROĞLU2 \\ ${ }^{1}$ Kalkinma Neighborhood, Yeşim Street, No:12, Fatih Apartment, 61080, Ortahisar / Trabzon, Turkey \\ ${ }^{2}$ Kemerkaya Neighborhood, Balıkpazarl Street, No:14, Birlik Apartment, 61100, Ortahisar / Trabzon, Turkey \\ ORCID ID: Muammer KURNAZ: https://orcid.org/0000-0002-0498-0208; Ali İhsan EROĞLU: https://orcid.org/0000-0001-7642-4086
}

\begin{abstract}
Received: 09.06.2020 Accepted: 05.07.2020 Published online: 25.08.2020 $\quad$ Issue published: 31.12 .2020
Abstract: Species are affected by many biotic and abiotic variables while distributed in the geographical areas on the earth. These factors constitute all the life-related needs of the species in their habitats and constitute the ecological barrier between the species. In this study, Eremias strauchi was recorded for the first time from Erzurum province and this record constitutes the westernmost locality of the species. Moreover, information on the bioclimatic factors in determining the distribution of the species in Turkey is given. This shows that E. strauchi has adapted to the terrestrial climate and prefers its habitat requirements accordingly.
\end{abstract}

Keywords: MaxEnt, Horasan, Erzurum, Lacertidae, Ecological Niche Model.

\section{Eremias strauchi Kessler, 1878'in Türkiye'deki En Batı Kaydı ve Potansiyel Yayılışı}

Öz: Türler yeryüzündeki coğrafi alanlarda yayılış gösterirken birçok biyotik ve abiyotik değişkenden etkilenmektedirler. Bu faktörler, türlerin yaşadıkları habitatlardaki yaşam ile ilgili bütün gereksinimlerini oluşturup türlerin birbirleri arasındaki ekolojik bariyerini oluşturmaktadır. Sunulan bu çalışmada, Eremias strauchi'nin Erzurum (Horasan) ilinden ilk defa lokalite kaydı yapılmış olup bu kayıt türün yayılış alanındaki en batı lokalitesini teşkil etmektedir. Ayrıca türün Türkiye'deki yayılışının belirlenmesindeki biyoiklimsel faktörlerin neler olduğu hakkında da bilgiler verilmiştir. Bu durum E. strauchi'nin karasal iklime uyum sağladığını ve habitat gereksinimlerini de bu yönde tercih ettiğini göstermektedir.

Anahtar kelimeler: MaxEnt, Horasan, Erzurum, Lacertidae, Ekolojik Niş Modeli.

\section{Giriş}

Eremias (Fitzinger, 1834) cinsine ait kertenkeleler Dünya'da 40 tür ile temsil edilmektedir (Uetz, Freed, \& Hošek, 2020) ve Kuzey Çin, Moğolistan, Kore, Orta ve Güneydoğu Asya'dan Güneydoğu Avrupa'ya kadar yayılış göstermektedirler (Rastegar-Pouyani \& Nilson, 1997; Anderson, 1999). Türkiye'nin sadece doğusunda yayılış gösteren bu cins, Türkiye'de üç tür (E. pleskei Nikolsky, 1905; E. strauchi Kessler, 1878 ve E. suphani Başoğlu \& Hellmich, 1968) ile temsil edilmektedir (Baran, Ilgaz, Avc1, Kumlutaş, \& Olgun, 2012). Bu türlerden biri olan E. strauchi ülkemizde çok dar bir dağılıma sahiptir ve Doğu Anadolu bölgesinde Iğdır, Ağrı ve Kars illerinde sınırlı alanlarda yayılış göstermektedir (Mertens, 1952; Clark \& Clark, 1973; Baran, 1980; Franzen, 1990; Mulder, 1995; Franzen \& Heckes, 1999; Baran et al., 2004; Altunışık, Gül, Özdemir, Tosunoğlu, \& Ergül, 2013; Düşen, Kumlutaş, Ilgaz, Yaka, \& Karadayı, 2013; Yıldız, İğci, Akman, \& Göçmen, 2018).

Eremias strauchi daha önceleri ülkemizde bilinmesine rağmen, ilk olarak Mertens (1952) tarafından Tuzluca (Sarıkamış)'dan bulunan örnekle Türkiye herpetofauna listesine eklenmiştir. Daha sonraki yılları müteakiben, Clark \& Clark (1973) türü Kağızman'nın 30 km güneyi ile Doğubayazıt'ın $2 \mathrm{~km}$ kuzeyinde tespit ederek rapor etmiştir. Bu bölgelerden farklı olarak Baran (1980) türün Iğdır'da da yayılış gösterdiğini bildirmiştir. Daha sonra yapılan bütün çalışmalarda A ğrı, Iğdır ve Kars illerinden türün varlığı rapor edilmiştir (Franzen, 1990; Mulder,
1995; Franzen \& Heckes, 1999; Baran et al., 2004; Altunış1k, Gül, Özdemir, Tosunoğlu, \& Ergül, 2013; Düşen, Kumlutaş, Ilgaz, Yaka, \& Karadayı, 2013; Yıldız, İğci, Akman, \& Göçmen, 2018). Sunulan bu çalışmanın amacı literatürde belirtilen bu üç ilin haricinde türün Erzurum'da da yayılış gösterdiğini rapor etmek ve türün Türkiye'deki potansiyel yayılışı belirleyip habitat tercihleri hakkında bilgiler vermektir.

\section{Materyal ve Metot}

Türe ait bütün lokalite kayıtları literatür ve bu çalışma kapsamındaki arazi çalışmasından elde edilmiştir (08.05.2017, Horasan, Erzurum, leg. Muammer Kurnaz \& Ali İhsan Eroğlu). Toplamda E. strauchi türüne ait dört ilden ve 18 lokaliteden koordinat verisi toplanmıştır. Toplanan koordinat verilerinin hepsi ondalık veri sisteminde her lokalite için ayarlanmış ve virgülle ayrılmış (CSV) Excel dosyası olarak kaydedilmiştir (Tablo 1).

Türün yayılış modelini oluşturmak için, öncelikle 19 biyoiklimsel değişken (30 arc saniyelik) (Tablo 2) www.worldclim.org internet sitesinden indirilmiştir (Hijmans, Cameron, Parra, Jones, \& Jarvis, 2005). Buna ek olarak türün yayılışına etki edebilecek olan yükselti (Jarvis, Reuter, Nelson, \& Guevara, 2008) verisi (SRTM30) ile eğim (Fischer et al., 2007) verileri elde edildi. Bu veriler dünya ölçeğinde olduklarından verileri Türkiye ölçeğine uyarlamak için, ArcGIS 10.3 programindan yararlanıldı. On dokuz biyo-iklimsel veri ve iki tane topografik veri ArcGIS programında Türkiye ölçeğine maskelendi. Bu yirmi bir veri ENMTools 1.4 programinda Pearson 
korelasyon analizine tabi tutuldu ve $r>0.75$ olan veriler yayılışı negatif etkileyeceğinden dolayı analizden dışarı çıarılmıştır (Warran, Glor, \& Turelli, 2010).

Türün yayılışını belirlemek için MaxEnt 3.3.3k (Philips, Anderson, \& Schapire, 2006) programindan yararlanılmıştır. CSV formatına dönüştürülmüş koordinat verileri ile korelasyonu 0.75 'ten düşük olan veriler analize tabii tutulmuştur. MaxEnt programı 0.00001 yakınsama eşiği, 500 en yüksek tekrarlama ve 0.5 düzenleme çarpanı ile çalıştırılmıştır. Ayrıca oluşum verilerinin \%25'i test puanları olarak ayrılmıştır ve dağılımı belirlemek için 10.000 arka plan noktası kullanılmıştır. Son olarak da analizde on harita (on tekrar) oluşturulmuş ve en uygun yayılış haritası seçilmiştir. Verilerin yayılışa etki eden önemliliğini belirlemek için Jackknife testi yapılmıştır. Ayrıca AUC ve ROC verilerinden de yararlanılmıştır. Alıcı çalışma karakteristiği (ROC) eğrisinin sonucu, model duyarlılığ1 için önemlidir ve 1 'e en yakın eğri altındaki alanın değeri (AUC) en iyi model performansını göstermektedir. 0.5'e yakın bir değer, türün yayılışının koordinat verileri ile uyumlu olmadığını, 0.5-0.8 arasındaki değerler türün yayılışının test dağılışı ile uygun olduğunu ve 0.8-1 arası veriler de bu uygunluğun çok yüksek derecede olduğunu göstermektedir (Raes \& ter Steege, 2007; Gallien Douzet, Pratte, Zimmermann, \& Thuiller, 2012).

Tablo 1. E. strauchi'nin potansiyel yayılışının hesaplanması için kullanılan bütün koordinat verileri.

Table 1. All coordinate data used for the estimation of E. strauchi's potential distribution.

\begin{tabular}{lccl}
\hline Lokalite & Enlem & Boylam & Literatür \\
\hline Karakurt & 40.131660 & 42.816797 & Mulder, 1995 \\
Kağızman'ın 30 km güneyi & 40.100375 & 43.296667 & Clark \& Clark, 1973 \\
Tuzluca & 40.040668 & 43.655549 & Mertens, 1952 \\
Iğdır'ın 25 km kuzeybatısı & 40.002358 & 43.919017 & Franzen \& Heckes, 1999 \\
Iğdır & 39.924147 & 44.054482 & Baran, 1980 \\
Taşburun & 39.982358 & 44.261832 & Baran, 1980 \\
Iğdır'ın 10 km güneyi & 39.846636 & 44.057281 & Clark \& Clark, 1973 \\
Çilli & 39.732788 & 44.023227 & Baran, 1980 \\
Karabulak & 39.667431 & 44.051923 & Franzen \& Heckes, 1999 \\
Melekli & 39.946132 & 44.104925 & Altunış1k et al., 2013 \\
Aralık-Nahcivan arası & 39.840156 & 44.534944 & Düşen et al., 2013; Baran et al., 2004 \\
Aralık-Nahcivan arası & 39.821181 & 44.593908 & Düşen et al., 2013; Baran et al., 2004 \\
Torulpaşa Kışlası & 39.660589 & 44.796764 & Düşen et al., 2013; Baran et al., 2004 \\
Ağrı-İran Sınırı & 39.631311 & 44.471342 & Franzen, 1990 \\
Telçeker- Doğubayazıt & 39.449541 & 44.227126 & Yıldız et al., 2018 \\
Döşkaya- Tutak & 39.525510 & 42.489580 & Yildız et al., 2018 \\
Kılıçgediği- Tutak, & 39.615645 & 42.823858 & Yıldız et al., 2018 \\
Horosan & 40.109917 & 42.397700 & Bu çalışma \\
\hline
\end{tabular}

Tablo 2. Yayılış analizinde kullanılan biyoiklimsel değişkenler.

Table 2. Bioclimatic variables used in the distribution analysis.

\begin{tabular}{ll}
\hline Bio 1 & Yıllık ortalama sıcaklık \\
Bio 2 & Ortalama günlük sıcaklık aralığı (aylık ortalama[maks-min]) \\
Bio 3 & Eş sıcaklık (Bio2 x Bio7 / 100) \\
Bio 4 & Mevsimsel sıcaklık (Standart sapma x 100) \\
Bio 5 & Daha soğuk ayların minimum sıcaklığı \\
Bio 6 & Daha sıcak ayların maksimum sıcaklığı \\
Bio 7 & Yıllık sıcaklık aralığı (Bio 5-Bio 6) \\
Bio 8 & En yağışlı çeyreğin ortalama sıcaklığ1 \\
Bio 9 & En kurak çeyreğin ortalama sıcaklığı \\
Bio 10 & En sıcak çeyreğin ortalama sıcaklığ1 \\
Bio 11 & En soğuk çeyreğin ortalama sıcaklığ1 \\
Bio 12 & Yıllık yağ1ş \\
Bio 13 & En yağışlı ayda düşen yağmur \\
Bio 14 & En kurak ayda düşen yağmur \\
Bio 15 & Mevsimsel yağmur (aylık yağışın standart sapması) \\
Bio 16 & En yağışlı çeyreğin ortalama yağışı \\
Bio 17 & En kurak çeyreğin ortalama yağışı \\
Bio 18 & En sıcak çeyreğin ortalama yağışı \\
Bio 19 & En soğuk çeyreğin ortalama yağışı \\
\hline
\end{tabular}

\section{Sonuçlar ve Tartışma}

Sunulan bu çalışmada E. strauchi türünün Erzurum ilinden ilk kez bir lokalite kaydı verilmiştir. Bulunan bu yeni lokalite Kars-Erzurum sınırına çok yakın bir yerde olup türün daha önce bilinen Karakurt lokalitesine kuş uçuşu yaklaşık $40 \mathrm{~km}$ uzaklıktadır. Türün yaşadığı alan genellikle kumlu, az çayırlı ve taşların bulunduğu dik bir kayalık yamaçtan oluşmaktadır. Kars-Erzurum karayolunun hemen kenarında Aras nehrinin kuzeyinde konumlanmıştır. Alan sürüngen türü açısından oldukça zengindir ve E. strauchi bu alanda Darevskia parvula, Lacerta media, Ophisops elegans ve Parvilacerta parva ile simpatrik yaşamaktadır.
Günümüz biyoiklimsel koşulları altında E. strauchi türü için yapılan yayılış analizinde türün yayılışının habitat gereksinimleri ile uygun olduğu ortaya çıkmıştır (Şekil 1). Bu analizler sonucunda on dokuz biyoiklimsel değişkenlerden beş tanesi (Bio-3, Bio-7, Bio-9, Bio-18 ve Bio-19) ile topografik değişkenlerden yükselti değişkeni türün yayılışına büyük ölçüde etki etmektedir. Bu değişkenlerden Bio-19 ve Bio-7 türün yayılışına en çok etki eden biyoiklimsel değişkenlerdir. Bu durum yayılış içerisinde yaklaşık \%90'l1k bir dilimi oluşturmaktadır (Tablo 3). Bu iki değişkenin özellikle bu türün yayılışını belirlemesinin nedeni, türün hem sıcak hem de soğuk ortamları sevmesidir. Bu durum türün yayılış gösterdiği karasal iklimle aslında karakteristik bir durumdur. Yayılış için yapılan jacknife analizinde Bio-19 biyoiklimsel değişkeninin türün yayılışı için en kullanışlı değişken olduğu ve tek başına kullanıldığı zaman türün yayılışını belirleyebileceği ortaya çıkmıştır (Şekil 2). Yapılan analiz sonucunda bulunan alıcı çalışma karakteristiği (ROC) eğrisinin sonucu, model duyarlılığı ile uyumlu bulunmuştur ve eğri altındaki alanın değeri (AUC) $0.989 \pm$ 0.012 olarak bulunmuştur. Bu değerin 1'e çok yakın olması türün coğrafi yayılışının yapılan analiz ile uyumlu olduğunu göstermektedir. Ayrıca günümüzdeki biyoiklimsel ve coğrafi değişkenlerin, türün yayılışına en uygun biçimde etki ettiğini göstermektedir. Standart sapmanın sıfıra çok yakın olması ise yapılan analizin hata payının çok düşük olduğunu ve türün habitat seçiminin bu değişkenlerle uyumluluğunu göstermektedir.

Sürüngen türleri yıllık sıcaklık değişimlerinden oldukça etkilenmektedirler ve bu durum onların yıllık 
aktivitelerini de belirlemektedir (Adolph \& Porter, 1993). Örneğin yüksek rakımda yaşayan türlerin yaşam döngüsü alçak rakımda yaşayanlardan daha kısadır. E. strauchi genellikle $1000 \mathrm{~m}$ rakımın üzerinde yaşayan bir kertenkele türüdür. Yaşadığı habitatlar genellikle kurak ve bozkır iklimi özelliği gösterdiğinden dolayı, yıllık aktivitelerini daha kısa zamanda tamamlayıp alçak rakımlarda yaşayan kertenkele türlerinden daha önce hibernasyona girmek zorundadırlar. Bu durumu etkileyen faktörlerden en önemlisi yıllık sıcaklık değişimleridir. Sunulan bu çalışmada Bio-7 değişeni \%9 oranında türün yayılışına etki etmiştir. Bu durum E. strauchi türünün Türkiye'de y1llık sıcaklık değişimlerinde oldukça etkilendiğini göstermektedir.

Tablo 3. E. strauchi'nin potansiyel yayılışına katkıda bulunan biyoiklimsel değişkenler ve katkı oranları.

Table 3. Bioclimatic variables contributing to the potential distribution of E. strauchi and their contribution rates.

\begin{tabular}{lll}
\hline No & Değişkenler & Katkıları (\%) \\
1 & Bio 19 & 82.9 \\
2 & Bio 7 & 9 \\
3 & Bio 3 & 3.2 \\
4 & Bio 18 & 1.9 \\
5 & Bio 9 & 1.7 \\
6 & Yükseklik & 1.2 \\
\hline
\end{tabular}

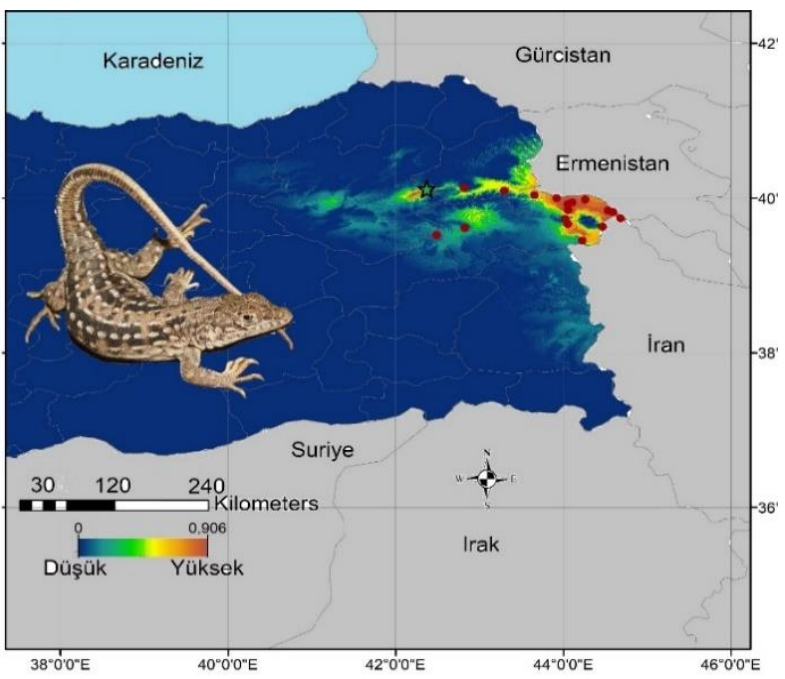

Şekil 1. İklimsel ve coğrafik değişkenler altında E. strauchi türünün potansiyel dağılışı (Yıldız şekli yeni lokalite kaydını temsil etmektedir).

Figure 1. The potential distribution of E. strauchi under climatic and geographic variables (Star shape represents new locality record).

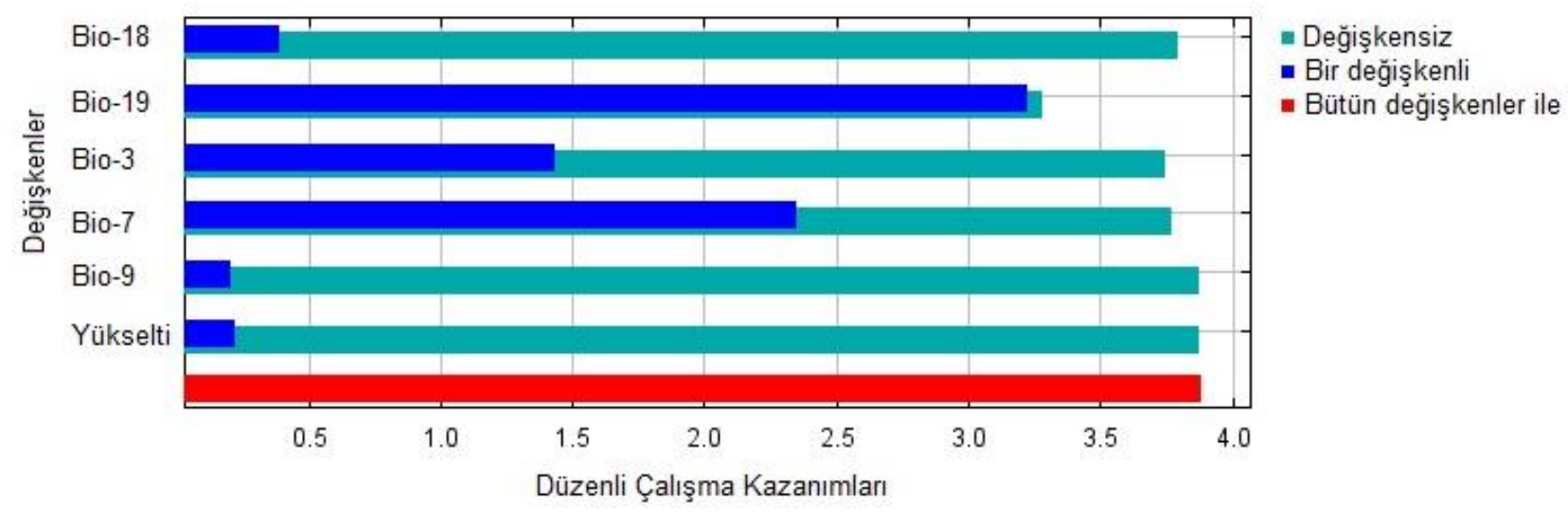

Şekil 2. Yayılış modelinde kullanılan değişkenlerin önemliliklerinin jackknife testi sonuçları.

Figure 2. Jackknife test results of the significance of variables used in the distribution model.

Nişin korunması, farklı türler arasındaki atasal özellikleri koruyan bir olgudur (Wiens \& Graham, 2005). Habitat tercihi bir türün yayılış alanını belirlemesi için olmazsa olmazlarındandır ve bu da bir türün hem biyocoğrafyasını hem de diğer türlerden ayrılmasını sağlayacak ekolojik nişini oluşturmaktadır (Kurnaz \& Hosseinian-Yousefkhani, 2019). Uygun habitatların az oluşu ya da ortadan kalkması bir türün yaşam alanlarını daraltır ve türün tehlike altına girmesine neden olabilir. Bu da bir türün yaşaması için tercih edebileceği alanları sınırlar. Literatür çalışmaları, E. strauchi türünün Türkiye'de çok dar bir alanda yayılış gösterdiğini ortaya çıarmıştır (Franzen, 1990; Mulder, 1995; Franzen \& Heckes, 1999; Baran et al., 2004; Altunışık, Gül, Özdemir, Tosunoğlu, \& Ergül, 2013; Düşen, Kumlutaş, Ilgaz, Yaka, \& Karadayı, 2013; Yıldız, İğci, Akman, \& Göçmen, 2018). $\mathrm{Bu}$ tür IUCN'de LC kategorisinde görünse de, bu kategorinin Türkiye için tekrar gözden geçirilmesi gerekmektedir. Türkiye'de dar bir yayılış gösteren tür, İran'da daha geniş yayılış gösterir ve bu durum türün kategorisini düşük endişe (LC) kategorisine sokmaktadır.

Türler, yayılışlarını belirlemek için biyotik (rakip veya öngörücüler gibi) ve abiyotik (çevresel faktörler veya mikro habitat yapıları gibi) faktörlerin de dâhil olduğu birçok değişkenden etkilenmektedirler (Hosseinian Yousefkhani, Rastegar-Pouyani, \& Aliabadian, 2016). İklim değişkenleri de türlerin dağılımını sınırlandıran en önemli faktörlerdendir (Cahill et al., 2013). Bu değişkenler türlerin alansal tercihlerini tercih etmelerinde ve bu alanlardaki nişlerini belirlemelerinde oldukça önemlidir (Peterson, Soberon, \& Sanchez-Cordero, 1999). E. strauchi'nin Türkiye' deki yayılışını belirlemek için soğuk ve kurak alanları tercih etmek ve hatta bu yayılışa yüksekliğin de katkıda bulunduğunu göz önünde bulundurmak gerekir. Yaptığımız çalışma da buna yönelik olduğu için bu da çalışmanın önemli bulgularından biridir. Buna benzer literatürde de E. strauchi için hemen hemen aynı sonuç bulunmuştur (Hosseinian Yousefkhani, Rastegar-Pouyani, \& Aliabadian, 2016). Ayrıca türün İran populasyonları için yapılan potansiyel yayılış analizlerinde türün yayılışına Bio-3, Bio-8, Bio-9, Bio-18 ve Bio-19 biyoiklimsel değişkenleri ile topografik verilerinden eğim verisinin etki ettiği görülmektedir (Hosseinian Yousefkhani, Rastegar-Pouyani, \& Aliabadian, 2016). Bu durum sunulan bu çalışmada elde edilen bulgularla nerede ise aynı olduğu, türün hem İran hem de Türkiye'de yayılış göstermek için aynı 
biyoiklimsel değişkenleri kullandığını göstermektedir. Ancak sunulan bu çalışmada Bio-19 verisi türün yayılışına \% 82,9 katkı sağlarken İran populasyonlarında \%34,4 katk1 sağlamaktadır. Aradaki bu farklılıkların iki ülke arasındaki hem topografik farklılıktan hem de türün iki ülke arasındaki küçük de olsa biyoiklimsel gereksinimlerinin farklı olabileceğinden kaynaklanabilir. $\mathrm{Bu}$ da Türkiye populasyonları ile İran populasyonlarının az da olsa farklılık gösterebileceğini ortaya koyabilir. Türün İran populasyonları arasındaki taksonomik durumu moleküler belirteçler kullanılarak ortaya çıkarılmıştır (Rastegar-Pouyani, Hosseinian Yousefkhani, \& Wink, 2015). Ancak bu çalışmada Türkiye'den herhangi bir örnek kullanılmamıştır. Türkiye populasyonlarından elde edilecek örnekler ile İran populasyonları karşılaştırılıp ortaya çıkan ekolojik farklılıkların moleküler ve morfoloji açısından da farklı olup olmadığı da bir çalışma konusunu teşkil edebilir. Sonuç olarak, bu çalışma hem türün potansiyel yayılışını belirleme hem de türün en batıdaki yayılış alanının (Horasan) tespit edilmesi açısından oldukça önemlidir. Ayrıca bu çalışma ile türün daha önceden yayılış gösterdiği üç ile ilaveten Erzurum' da da uygun habitatlarda yayılış gösterebileceği ortaya koyulmuştur. Dahası türün Türkiye'deki habitat tercihlerinin ve bu tercihlere etki eden biyoiklimsel değişkenlerin belirlenmesi açısından da oldukça önemli bir çalışmadır. Buna ilaveten bu çalışmada elde edilen yayılış bulgularının literatürde verilen bulgularla uygun olduğu görülmüştür.

\section{Kaynaklar}

Adolph, S.C., \& Porter, W.P. (1993). Temperature, activity, and lizard life histories. The American Naturalist, 142, 273-295.

Altunışık, A., Gül, Ç., Özdemir, N., Tosunoğlu, M., \& Ergül, T. (2013). Age structure and body size on the Strauch's racerunner, Eremias strauchi strauchi Kessler, 1878. Turkish Journal of Zoology, 37(5), 539-543.

Anderson, S.C. (1999). The Lizards of Iran. Society for the Study of Amphibians and Reptiles. Contributions to Herpetology, 15, 1-442.

Baran, İ. (1980). Doğu ve Güney Anadolu'nun Kaplumbağa ve Kertenkele Faunası. Ege Üniversitesi Fen Fakültesi Dergisi, B (IV), 203-215.

Baran, İ., Ilgaz, Ç., Avcl, A., Kumlutaş, Y., \& Olgun, K. (2012). Türkiye Amfibi ve Sürüngenleri. Ankara, Turkey: TÜBITTAK Popüler Bilim Kitapları.

Baran, İ., Kumlutaş, Y., Tok, C.V., Ilgaz, C., Kaska, Y., Olgun, K., Türkozan, O., \& Iret, F. (2004). On two herpetological collections made in East Anatrolia (Turkey). Herpetozoa, 16 (3/4), 99-114.

Cahill, A.E., Aiello-Lammens, M.E., Fisher-Reid, M.C., Hua, X., Karanewsky, C.J., Ryu, H.Y., Sbeglia, G.C., Spagnolo, F., Waldron, J.B., Warsi, O., \& Wiens, J.J. (2013). How does climate change cause extinction? Proceedings of the Royal Society of London, 280, 2012890.

Clark, R.J., \& Clark, E.D. (1973). Report on a collection of amphibians and reptiles from Turkey. Occaasiona Papers of the California Academy of Sciences, 104, 1-62.

Düşen, S., Kumlutaş, Y., Ilgaz, Ç., Yaka, H., \& Karadayi, F. (2013). Hemlinth parasites of the three Racerunner Lizards: Eremias pleskei Nikolsky, 1905 (Pleske's Racerunner -Transcaucasian Racerunner), Eremias strauchi Kessler, 1878 (Strauch's Racerunner) and Eremias suphani Basoglu \& Hellmich, 1968 (Suphan Racerunner) collected from Eastern part of Turkey. Helminthologia, 50(2), 108-111.

Fischer, G., Nachtergaele, F., Prieler, S., van Velthuizen, H.T., Verelst, L., \& Wiberg, D. (2007). Global Agro-ecological Zones Assessment for Agriculture (GAEZ 2007). IIASA, Laxenburg, Austria and FAO, Rome, Italy: http://webarchive.iiasa.ac.at/Research/LUC/ProductsDatasets/global-terrain-slope.html (erişim tarihi: 21.09.2019).

Franzen, M. (1990). Die Eidechsenfauna (Lacertidae) der Türkei. Die Eidechse, 1, 3-9 (in German).

Franzen, M., \& Heckes, U. (1999.) Eremias suphani Başoğlu \& Hellmich, 1968 und Eremias strauchi KESSLER, 1878 in der östlichen Türkei: Diagnostische Merkmale, Verbreitung und Lebensräume (Sauria: Lacertidae). Salamandra, 35(4), 255-266.
Gallien, L., Douzet, R., Pratte, S., Zimmermann, N.E., \& Thuiller, W. (2012). Invasive species distribution models - how violating the equilibrium assumption can create new insights. Global Ecology and Biogeography, 21, 1126-1136.

Hijmans, R.J., Cameron, S.E., Parra, J.L., Jones, P.G., \& Jarvis, A. (2005). Very high resolution interpolated climate surfaces for globalland areas. International Journal of Climatology, 25, 1965-1978.

Hosseinian-Yousefkhani, S.S., Rastegar-Pouyani, E., \& Aliabadian, M. (2016). Ecological niche differentiation and taxonomic distinction between Eremias strauchi strauchi and Eremias strauchi kopetdaghica (Squamata: Lacertidae) on the Iranian Plateau based on ecological niche modeling. Italian Journal of Zoology, 83(3), 408-416.

Jarvis, A., Reuter, H.I., Nelson, A., \& Guevara, E. (2008). Hole-filled SRTM for the globe Version 4, available from the CGIAR-CSI SRTM $90 \mathrm{~m}$ Database: http://srtm.csi.cgiar.org (erişim tarihi: 21.09.2019).

Kurnaz, M., \& Hosseinian-Yousefkhani, S.S. (2019). Ecological niche divergence between Darevskia rudis and D. bithynica (Lacertidae) in Turkey. Biologia, 1-6. https://doi.org/10.2478/s11756-019-00374-0

Mertens, R. (1952). Amphibien und Reptilien aus der Turkei. İstanbul Üniversitesi Fen Fakültesi Mecmuası, B17, 40-75 (in German).

Mulder, J. (1995) Herpetological observations in Turkey (1987-1995). Deinsea, 2, 51-66.

Peterson, A.T., Soberon, J., \& Sanchez-Cordero, V. (1999). Conservatism of ecological niches in evolutionary time. Science, 285, 1265-1267.

Phillips, S.J., Anderson, R.P., \& Schapire, R.E. (2006). Maximum entropymodeling of species geographic distributions. Ecological Modelling, 190, 231-259.

Raes, N., \& Ter Steege, H. (2007). A null-model for significance testing of presence only species distribution models. Ecography, 30, 727-736.

Rastegar-Pouyani, N., \& Nilson, N. (1997). A new species of Eremias (Sauria: Lacertidae) from Fars Province, South-Central Iran. Russian Journal of Herpetology, 4, 94-101.

Rastegar-Pouyani, E., Hosseinian-Yousefkhani, S.S., \& Wink, M. (2015). Taxonomic reevaluation of Eremias strauchi strauchi Kessler, 1878 and Eremias strauchi kopetdaghica Szczerbak, 1972, based on nuclear and mitochondrial DNA sequences (Reptilia: Lacertidae). Zoology in the Middle East, 61, 118-124.

Uetz, P., Freed, P., \& Hošek, J. (2020). The Reptile Database, http:/ / www.reptile-database.org, accessed in 08 June 2019.

Warren, D.L., Glor, R.E., \& Turelli, M. (2010). ENMTools: A toolbox forcomparative studies of environmental niche models. Ecography, 33, 607-611.

Wiens, J.J., \& Graham C.H. (2005). Niche conservatism: integrating evolution, ecology, and conservation biology. Annual Review of Ecology, Evolution, and Systematics, 36, 519-539.

Yıldız, M.Z., İ̆gci, N., Akman, B., \& Göçmen, B. (2018). Results of a herpetological survey in the Province of Ağrı (east Anatolia, Turkey) (Anura; Testudines; Squamata). Herpetozoa, 31(1/2), 47-59. 